\title{
Celestina: Documento bibliográfico (suplemento número 32)
}

\author{
Devid Paolini \\ The City College of New York
}

[Mantener al día una bibliografía es ya por sí mismo una empresa bastante difícil. Si a esto se le añade que quien se ocupó de todo ello (Joseph T. Snow) antes de designarme como su sucesor ha sido y es uno de los más grandes expertos de La Celestina (de ahora en adelante $L C$ ), además de fundador y editor durante unos 25 años de la presente revista, será bastante fácil entender la "presión», o mejor dicho, la responsabilidad que siente quien esto escribe. De todos modos, he intentado e intentaré cumplir con mi nueva tarea lo mejor posible y espero no decepcionar la confianza que mi ilustre predecesor, a quien sinceramente agradezco, ha puesto en mí. Lo que se encontrará a continuación no es toda harina de mi costal. El siempre amable Snow me ayudó muchísimo en este momento de transición del suplemento bibliográfico. De hecho, me pasó unas cuantas entradas ya anotadas y también a lo largo del pasado y del presente año me envió reseñas, notas, recordatorios, informaciones acerca de nuevas ediciones, etc. Todo lo que es suyo lo he indicado al final con la sigla: [JTS]. Además me ha ayudado el profesor Fernando Rodríguez-Gallego anotando un artículo en alemán (marcado al final [FRG]). Conste aquí mi gratitud hacia los dos. Espero que también otros profesores, colegas, amigos, y todas aquellas personas interesadas en $L C$ quieran colaborar señalándome libros, artículos, reseñas, o todo material que gire alrededor de esta obra maestra de finales del siglo XV (aun porque, como dice la vieja alcahueta en el primer acto, «los bienes, si no son comunicados, no son bienes»). Los que quieran ponerse en contacto conmigo podrán hacerlo en la siguiente dirección de correo electrónico: dpaolini@ccny.cuny.edu. Muchísimas gracias de antemano, DP] 
2060. ALONSO, Álvaro, “'Perlas y rubíes’: una imagen italiana entre Santillana y la Celestina», en PAOLINI, 26-35.

Análisis detenido de las imágenes "perlas» y "rubíes» en la literatura castellana del siglo XV con especial referencia a la $L C y$, en particular, a la descripción de Melibea que da Calisto en el acto I ("los dedos luengos, las uñas en ellos largas y coloradas, que parecen rubíes entre perlas»).

2061. ÁLVAREZ-MORENO, Raúl, "Amarse a sí, procurar su interés y vivir su ley: los más de tres jaques al bien común en Celestina», en PAOLINI, 36-53.

El artículo trata del conflicto entre individuo y sociedad en la obra, mostrando cómo en $L C$ tres de los componentes fundamentales, según la escolástica, del «bien común» (virtud, caridad y justicia distributiva), se subvierten hasta presentar una redefinición irónica de estos

2062. ANDRES, Christian, «La question de la modernité de La Celestine: genèse, enjeux et perspectives», Les Langues Néo-Latines 347 (2008), 33-52.

Trata de la modernidad de $L C$, en su vertiente socio-histórica (señalando los aportes principales de los estudios de Maravall y Pérez), genérica (como obra sui generis, atípica) y existencial (profundidad sicológica de los personajes, nueva sensibilidad hacia la muerte y la Fortuna, visión paródica e irónica del mundo, su ambigüedad, etc.).

2063. ARMISTEAD, Samuel G., James T. MONROE y Joseph H. SILVERMAN, «Was Calixto's Grandmother a Nymphomaniac Mamlük Princess? (A Footnote on «Lo de tu abuela con el ximio» [La Celestina, Aucto 1])», eHumanista 14 (2010), 1-23.

Se ocupa de un pasaje controvertido de $L C$, precisamente, de lo que le dice Sempronio a su amo Calisto en el acto I acerca de su «abuela con el ximio" y "el cuchillo de [su] abuelo». Se relaciona esta referencia con el cuento "La princesa y el mono" de Las mil y unas noches donde aparece una joven tan lujuriosa que sólo puede satisfacer su deseo con tal animal, proverbialmente muy activo sexualmente. Al final, un carnicero matará al mono con un cuchillo, casándose con la princesa. Tal vez una versión similar conocida en la península ibérica haya sido la fuente del pasaje en cuestión.

2064. BALLESTEROS, Rafael, fernando de rojas acostado sobre su propia mano (I). Málaga: Rafael Inglada, 1999. Rústica [7pp].

Más que un poemario, son frases que se imaginan pasando por la mente de "Hernando de Rojas» en que se destacan el vacío, las som- 
bras y el agnosticismo ("Yo solo creo en el dios que nos desprecia»). Hay, en esta entrada y en la siguiente, menciones de Toledo y Talavera, dos ciudades vinculadas con Rojas. [JTS]

2065. BALLESTEROS, Rafael, fernando de rojas acostado sobre su propia mano (II). Málaga: Rafel Inglada, 2002. Rústica [12pp].

Véase la entrada anterior.

2066. BERNALDO DE QUIRÓS, José Antonio, «Comentarios a la hipótesis de García Valdecasas sobre la gestación de La Celestina», Espéculo 30 (2005), sin paginación. (http://www.ucm.es/info/especulo/numero30/garvalde.html).

Repasa detenidamente las principales tesis del estudio de García Valdecasas señalando méritos y defectos. Concluye considerando muy verosímil la posibilidad de que el texto originario que Rojas encontró llegaba hasta el acto XIV y que a él sólo se deben los dos actos finales de la Comedia, el Tratado de Centurio, y diferentes interpolaciones a lo largo de toda la obra.

2067. BLANCO WHITE, José María, "Celestina». En sus Artículos de crítica e historia literaria. Edición, introducción y notas de Fernando Durán López. Sevilla: Fundación José Manuel Lara, 2010, 159-189.

El estudio apareció originalmente en Variedades o el Mensajero de Londres, t. I, n. 3 (1-Iv-1824), 224-246. En él Blanco White defiende la autoría única de Rojas, transcribe una parte de la obra y sitúa su acción en Sevilla. Sigue una carta de 1837 del autor a Rose Lawrance donde vuelve a defender el papel de Rojas como único autor.

2068. BURGOYNE, Jonathan, «El juego paremiológico en La Celestina, Acto I», en PAOLINI, 54-68.

Trata de la interacción de los proverbios que, numerosos, salpican el acto I y tienen como objetivo principal el de suscitar la hilaridad. Se analiza también la última escena, allí donde tiene lugar la llamada «seducción de Pármeno». Esta sobreabundancia de sentencias se debería a una ironía toda medieval que se burla no sólo de la costumbre de citar refranes, sino también de la mentalidad (toda proverbial) de la época.

2069. CAMPOS, Axayácatl y Daniel GUTIÉRREZ TRÁPAGA, eds. Estudios de Alan Deyermond sobre la "Celestina". In memoriam. Publicaciones de Medievalia 40. México, D.F.: UNAM, IIFL, 2010.

Recoge quince artículos de Alan Deyermond dedicados a $L C$, algunos traducidos por primera vez al español. 
2070. CANET VALLÉS, José Luis, «La Celestina y el paulinismo», en PAOLINI, 69-83.

Sitúa a la obra maestra española en el debate intelectual de la época sobre la filosofía moral y, en particular, sobre la felicidad y el sumo bien. Relaciona los ataques de San Pablo a los que buscan la sabiduría, vanidad del mundo, con los de Lorenzo Valla a los estoicos y los escolásticos. Todos los personajes de $L C$ se muestran dignos de tales críticas, puesto que debaten como paganos sin ninguna intención ni voluntad de querer llegar al sumo bien. Además, no siguen sino los preceptos que el Apóstol desaconseja, señalando así el carácter ex contrariis de la obra.

2071. CANTALAPIEDRA EROSTARBE, Fernando, "Alisa y Celestina, las comadres de la tenería", en Estudios sobre lengua, literatura y mujer, ed. $M^{a}$ Isabel Sancho Rodríguez et al. (Jaén: Universidad, 2006), 63-130.

Se ocupa de los personajes femeninos así como aparecen en la CCM. En particular, compara Celestina con Alisa, y Areúsa con Melibea. El intento principal es el de demostrar que entre los dos grupos sociales al que pertenecen las cuatro mujeres mencionadas (Alisa y Melibea; Celestina y Areúsa) no hay un contraste y un antagonismo tan fuerte como suele pensar la crítica. De una lectura cuidadosa de la Comedia se desprende que la familia de la joven enamorada no era tan noble y rica come se cree. Presenta además una posible explicación del origen del nombre de Alisa.

2072. CIORDIA, Martín José, «El movimiento europeo antierótico en las artes de amores de fines del XV y principios del XVI», Bulletin of Spanish Studies 84.8 (2007), 989-1006.

Relaciona $L C$ con dos tratados italianos anti-cortesanos, el Contra amores (1465) de Platina y el Anteros (1496) de Fregoso, con el objetivo de determinar los puntos de contacto que estas tres obras tienen y también si se pueden considerar parte del género llamado «arte de amores».

2073. CLOUD, Christine, "Girls Gone Wild' Medieval Spain Edition: A Cognitive, Revolutionary Approach to the Presentation of Female Sexuality in La Celestina», Celestinesca 33 (2009), 19-36.

A través de un análisis que se basa en la psicología evolutiva junto a una crítica cognitiva, la autora intenta demostrar cómo Rojas dibujó, en su obra maestra, a un personaje femenino sexualmente descontrolado. Esto con el objetivo de denunciar la marginalización en la que vivían los conversos como él. 
2074. CULL, John T., "Celestina's veritas: Fetishizing the Salve / salve of Healing Wine», Celestinesca 33 (2009), 39-56.

El autor habla de la relación de Celestina con el vino y se detiene, en particular, en el elogio que esta le dedica en el acto 9. Considera a la alcahueta como una pseudo-sacerdotisa, tanto cristiana (durante el banquete) como dionisíaca (por su afición/adoración a la bebida). Termina con el estudio de las referencias a las serpientes que se encuentran a lo largo de la obra, en asociación con el mito de Tiresias.

2075. CULL, John T., "A Possible Influence on the Burgos 1499 Celestina Illustrations: The German 1486 Translation of Terence's Eunuchus», La corónica 38.2 (2010), 137-160.

Compara algunos de los grabados de la traducción alemana del Eunuchus de 1486 con los de la edición burgalesa de la CCM. Llega a la conclusión de que la primera haya podido influir en la composición de las ilustraciones de la segunda, a diferencia de Rodríguez-Solás (véase, en el suplemento bibliográfico anterior, Celestinesca 33 [2009], núm. 1980) que indicaba en el impreso de Terencio de 1493 el posible modelo iconográfico.

2076. DEYERMOND, Alan, "Celestina's Ring of Power», en PAOLINI, 84-90.

Ofrece un resumen «visual» de LC relacionándola con el Señor de los anillos. La acción y el trasfondo principal de la obra pueden representarse con una serie de círculos concéntricos: una ciudad rodeada de murallas defiende la casa de Pleberio, que a su vez protege a Melibea que, por su parte, guarda su virginidad con el cordón. El Diablo en el hilado de la vieja barbuda, como el Anillo Único, lo desestabiliza todo y al caerse uno de los círculos toda la estructura se viene abajo (causando así la muerte de buena parte de los personajes).

2077. DI CAMILLO, Ottavio, "La comedia de Burgos en la tradición impresa de La Celestina: una revalorización», en "Medievalia \& Humanistica». Estudios sobre literatura española. Homenaje ofrecido por sus amigos y colegas. Al cuidado de Marithelma Costa \& Isaías Lerner (Salamanca: SEMYR, 2009), 161-274.

El volumen "Medievalia \& Humanistica" recoge unos trabajos del autor publicados en inglés y traducidos ahora al español. Entre ellos el último, aquí señalado, lo reseñó ya JTS en Celestinesca, 29 (2005), núm. 1727, y Celestinesca 33 (2009), núm. 1904. 
2078. DI CAMILLO, Ottavio, «When and Where was the First Act of $L a$ Celestina Composed? A Reconsideration", en PAOLINI, 91-157.

Un largo y detenido estudio que trata, principalmente, del primer acto de $L C$ y evidencia los puntos de contacto que este presenta con la cultura florentina de la segunda mitad del XV y que parece indicar su proveniencia. Se ocupa también, en un primer momento, de los principales estudios ecdóticos de la obra y, al final, de la relación entre el acto en cuestión y la carta introductoria de Piccolomini a la Historia de duobus amantibus, mejor conocida como Remedia amoris. Entre las hipótesis más sugerentes se encuentra la posibilidad de que el primer núcleo de la comedia estuviera escrito en latín. (Propone además como enmienda textual a "plebérico corazón", "phrenetico corazón». Véase el artículo de Fernández Rivera, en este mismo suplemento al núm. 2082, que se ocupa de la misma frase).

2079. DUBATTI, Jorge, «La Celestina en escenarios argentinos: observaciones comparatistas sobre las adaptaciones de Jorge Goldenberg (1993) y Daniel Suárez Marzal (2007)», Celestinesca 33 (2009), 59-68.

Analiza y compara las adaptaciones y reescrituras teatrales de $L C$ al cuidado de los dramaturgos Jorge Goldenberg (1993) y Daniel Suárez Marzal (2007), señalando analogías y divergencias.

2080. DUQUE, María, Cuaderno de comprensión lectora. "La Celestina». Fernando de Rojas. Madrid: Ediciones SM, 2008. Rústica, 32pp.

Trata de actividades coordinadas con la edición abreviada en 13 actos de Fran Zabaleta (ya reseñada por JTS en Celestinesca 33 [2009], núm. 2019). Lleva ilustraciones de J. R. Alonso. Para escolares jóvenes. [JTS]

2081. FERNÁNDEZ RIVERA, Enrique, "La autoría y el género de Celestina comentada», Revista de Filología Española 86.2 (2006), 259-276.

A través de un detenido análisis de las prolijas citas de Celestina comentada se ha podido reconstruir, en parte, la biblioteca del autor que la compuso. Fernández Rivera ha llegado a la conclusión de que éste era un doctor utriusque iuris con unos conocimientos de medicina que vivía en Valladolid o en sus alrededores. Las diferentes pruebas aportadas por el estudioso apuntan hacia el humanista vallisoletano Bernardino Daza (1528-158?), profesor de derecho de la Universidad de Valladolid y traductor del Liber emblematum de Alciato (Lyon, 1549).

2082. FERNÁNDEZ RIVERA, Enrique, «El plebérico corazón, Erasístrato y la plétora», Celestinesca 33 (2009), 71-85.

En uno de los pasajes más controvertidos del primer acto, allí donde Calisto se queja a Sempronio y pide ayuda a Erasístrato médico, el 
autor sugiere enmendar "plebérico corazón» por "pletórico corazón». Argumenta no sólo razones paleográficas, sino también el hecho de que desde la antigüedad se le conocía a Erasístrato tanto por haber curado a Antíoco como por imputar la mayoría de las enfermedades a la plétora, o abundancia de fluidos. (Trata también del mismo pasaje el largo artículo de Di Camillo, aquí descrito con el núm. 2078).

2083. FERNÁNDEZ RIVERA, Enrique, "El simbolismo de la menstruación en La Celestina», en PAOLINI, 158-170.

La exactitud con la que Rojas describe a la menstruación en diferentes pasajes de $L C$ parece demonstrar que tenía un conocimiento bastante profundo del argumento en cuestión. Además, entre los libros de su biblioteca, se contaba un ejemplar del De Secretis Mulieribus, tratado medieval dedicado a las afecciones ginecológicas de las mujeres. Según el autor estas referencias al dolor de la madre simbolizarían el leitmotiv de la caída o expulsión del paraíso.

2084. FERRERAS, Juan Ignacio, "La novela dialogada», último capítulo de su La novela en España: Historia, estudios y ensayos. Tomo I. Desde los orígenes a "La Celestina" (Madrid: La biblioteca del laberinto, 2009), 647-700.

Tras presentar las características de la novela dialogada y un catálogo de las obras que, según el estudioso, forman parte de este género (LC inclusive), pasa a analizar la obra maestra española (los cambios de Comedia a Tragicomedia, su éxito, la estructura, su fin moral, el monólogo, los apartes, las alusiones) y la celestinesca, que divide en tres grupos principales: intentos de versificación, continuaciones y obras con estructura similar.

2085. FRANCO VALDÉS, Brenda, "Una nueva visión femenina: Mirabella y Melibea», en Actas del XV Congreso de la Asociación Internacional de Hispanistas "Las dos orillas". Monterrey, México. Del 19 al 24 de julio de 2004, eds. B. Mariscal y A. González (México, D.F.: Fondo de Cultura Económica, Asociación Internacional de Hispanistas, Tecnológico de Monterrey, El Colegio de México, 2007), vol. 1, 341-349.

Compara las acciones de Mirabella en La historia de Grisel y Mirabella (1470-1495) de Juan de Flores con las de Melibea en LC. Lo que llama la atención de la estudiosa es el nuevo tipo de personaje femenino que se presenta en estas dos obras, un personaje que muestra una voluntad fuerte y firme que va más allá de los códigos sociales 
2086. FRIEDRICH, Sabine, "Kuplerinnen und Esel ohne Ohren. Transformationen ironischer Rede im Libro de buen amor und La Celestina», en Welterfahrung-Selbsterfahrung (Beihefte zur Iberoromania 16, Tubingen: Max Niemeyer, 2000), 23-46.

El artículo trata de la modernidad del personaje de Celestina con la que se inicia una nueva subjetividad, a través de la comparación con la figura tópica de la alcahueta desde Ovidio y, en la Edad Media, con la anus del Pamphilus y la Trotaconventos del Libro de buen amor. Aunque $L C$ empieza siguiendo el esquema típico de estas dos últimas obras, se va alejando de él por su ambivalencia y por la complejidad de que se dota al estereotipo. A través de sus apartes, de sus acciones y de lo que los demás dicen de ella, Celestina adquiere una personalidad y una complejidad de las que carecían sus predecesoras. [FRG]

2087. GALVÁN, Luis, «Intertexto, sentido, autoridad: 'el lobo viendo ganado' (Celestina, XIX)", Bulletin of Spanish Studies 84.6 (2007), 677-700.

Repasa las diferentes fuentes que se han propuesto para una estrofa de la canción de Lucrecia en el acto XIX de LC (Saltos de gozo infin tos / da el lobo viendo ganado, / con las tetas los cabritos, / Melibea con su amado). Por su parte, Galván ve en el pasaje en cuestión una alusión al Fedro de Platón, que representaría el intertexto de la estrofa de la criada.

2088. GARCÍA PASCUAL, Raquel, «Una revisión del mito de Celestina: Las conversiones, de José Martín Recuerda", Cuadernos de Investigación Filológica 29-30 (2003-2004), 285-306.

Repasa en detalle las distintas etapas y títulos de esta obra (19771981) en que figura una joven Celestina en la época de Enrique IV. El rey mismo aparece enmascarado, hay ambiente de constante carnaval y la obra está marcada por abundantes elementos grotescos. Hay recuerdos que entroncan con la obra clásica (Claudina vive, llamará Pármeno a su hijo no nacido, y Celestina recibe del rey la cicatriz de su cara). [JTS]

2089. GARGANO, Antonio. "'Omnia secundum litem fiunt'. Il mondo come conflitto nella Celestina di F. de Rojas», en su Le arti della pace. Tradizioni e rinnovamento letterario nella Spagna dei Re Cattolici (Nápoles: Liguori, 2008), 173-206.

Ensayo general que trata de la génesis de $L C$, el pasaje de CCM a TCM, en el que alude al problema del género literario y comenta los dos temas principales de la obra: la lujuria y el dinero (o, con otras palabras, el placer y el provecho). Aunque los cita en la bibliografía, parece desco- 
nocer los estudios que ponen en duda el papel de Rojas en relación con la obra.

2090. GARGANO, Antonio, «'Sacó mi secreto amor de mi pecho’: la confessione amorosa di Melibea (Celestina, X)", Medioevo Romanzo XxxII (ii della iv serie) Fasc I (2008), 116-134.

Una de las normas fundamentales del amor cortés era la de mantener secreto el sentimiento amoroso. Sin embargo, la pareja de jóvenes enamorados rompe, en más de una ocasión, con esta regla: Calisto llegando a desear que hayan testigos de su gloria; y Melibea (cuya actuación y confesión amorosa se estudian aquí detenidamente) anhelando dar rienda suelta al amor que siente por su amado.

2091. GILES, Ryan D. "Virgins and Harlots», capítulo 3 de su The Laughter of the Saints: Parodies of Holiness in Late Medieval and Renaissance Spain (Toronto: University of Toronto Press, 2009), 63-72.

El estudio se centra en el análisis de la parodia de los santos en diferentes textos, desde el Libro de buen amor hasta el Quijote. En el tercer capítulo, se dedican unas cuantas páginas al culto de la Magdalena en $L C$ y, en particular, de cómo Rojas se burla de la beata peccatrix a través de la caracterización del personaje de la alcahueta.

2092. GÓMEZ MORENO, Ángel, «Lecciones de hagiografía en La Celestina», en PAOLINI, 171-191.

Propone las vitae sanctorum como modelo ex contrariis de LC (tanto en la trama como en los personajes). Una devoción aparente, el uso de la retórica con fines pragmáticos y nada virtuosos, la avaricia, son aspectos que caracterizan a la vieja alcahueta y que la contraponen a los santos. Tampoco los otros personajes se salvan: los criados, sobre todo, se muestran egoístas y miedosos; Calisto, sacrílego, colérico e hipócrita; y Melibea, débil y totalmente abandonada al placer.

2093. GONZÁLEZ FERNÁNDEZ, Luis, «El verbo hecho carne: la muerte y la locura de Calisto (y algunas muertes más)», en MARTIN, 139-155.

Trata de las alusiones a la muerte de los dos personajes principales (Calisto, Melibea) en combinación con las muchas insinuaciones a la 'locura' y 'perder el seso', especialmente en el caso de Calisto, que es lo que le sucede cuando literalmente pierde sus sesos (acto XIX) y son recuperados por los criados (¿un guiño a una práctica de los judíosconversos?). El episodio del joven enamorado refleja lo acaecido en las muertes de Pármeno y Sempronio (sesos fuera), narrado por Sosia. Lo mismo sucede con la utilización del verbo (perder la razón), que se hace carne, vinculado con la muerte real. [JTS] 
2094. GUARDIOLA, Cristina, «El secreto oficio de la abeja: A Sociopolitical Metaphor in the Celestina», Diacritics 36.3-4 (2006), 147-155.

Celestina, con sus vaivenes, es el elemento conector entre el mundo aristocrático y prostibular. Además, es el personaje central de la sociedad descrita en la obra, y todo parece dar vueltas a su alrededor. Por eso se la compara con la abeja, animal político que en la tradición clásica, medieval y moderna representaba el modelo ideal de organización social. Pero, a través de su actuación, la vieja alcahueta realiza una crítica de la sociedad y muestra la corrupción de sus valores morales.

2095. GUARDIOLA, Cristina, "Transgresión sexual y el ejemplo moral: las Metamorfosis y la Tragicomedia», en Temas, motivos y contextos medievales, eds. A. González, L. von der Walde Moheno, C. Company (Publicaciones de Medievalia 33. México D.F.: El Colegio de México, UNAM, UAM, 2008), 303-312.

Se propone como modelo para el personaje del joven enamorado de LC a la ninfa Calisto de la versión moralizada de las Metamorfosis. Se relacionan así dos textos con fines ejemplares, y se explica la elección de un patrón femenino para la actuación demasiado apasionada del amante de la $T C M$, que termina por presentar a un Calisto afeminado.

2096. HEUSCH, Carlos, "La littérature selon Fernando de Rojas», Les Langues Néo-Latines 347 (2008), 53-66.

Se analiza la "poétique rojasienne», como la llama el autor del presente artículo, que se desprende de una lectura pormenorizada del prólogo en el que Rojas expresa claramente sus ideas acerca de su concepción del texto literario y de sus receptores (=lectores). Avanza por último la hipótesis de que Rojas no decidió añadir cinco autos a la Comedia y retocarla por contentar a los lectores deseosos de que se prolongaran los amores de la pareja de jóvenes enamorados, sino por una necesidad literaria personal del autor.

2097. HEUSCH, Carlos, "La literatura según Fernando de Rojas», Revista de poética medieval 22 (2009), 85-102.

Traducción española del artículo anterior.

2098. HEUSCH, Carlos, «Les avatars de Calixte de la Comedia à la Tragicomedia», en MARTIN, 157-175.

Presenta una nueva perspectiva sobre el Calisto de la CCM y el de la $T C M$, proponiendo una reescritura que le rescata de ser un amante cortesano ridículo y "loco». Sugiere, utilizando el texto celestinesco añadido y otros textos contemporáneos, que Calisto podría haber 
estado haciendo "teatro» o simulaciones en la CCM, pero llega, con el tiempo que le da la $T C M$, a ser un amante más sensato, sólo que demasiado tarde para evitar la tragedia. [JTS]

2099. HIGASHI, Alejandro, "Puntuación y prosodia en Celestina», en PAOLINI, 192-205.

Estudia la prosodia en $L C$ a partir de la puntuación de algunas ediciones tempranas de la obra, y señala la importancia de su lectura en voz alta.

2100. HIREL, Sophie, "La Célestine à la recherche du temps perdu», en MARTIN, 61-80.

De acuerdo con este artículo, en la obra no hay un concepto del tiempo real, ya que se difiere o se consume; los personajes están anclados en el presente ('hic et nunc'), no ven bien el futuro, y sus pasados (orígenes) se borran y presentan contradicciones. Quien domina el tiempo es Celestina, consciente de su edad de oro «veynte años ha» (es decir, antes de la formación de la Inquisición, que por sí sola produce muchos cambios en las vidas y deformaciones del tiempo vivido). [JTS]

2101. HOLLOWAY, Memory, "Penetrating Insight: The Celestina Series», capítulo 4 de su Making Time. Picasso's Suite 347 (New York-BrusselsOxford: Peter Lang, 2006), 97-122. Ilustrado.

Trata de los 347 aguafuertes realizados por el artista entre marzo y octubre de 1968. Unos cuantos (66) tuvieron como tema a $L C$ y son objeto de estudio en el capítulo citado.

2102. ILLADES, Gustavo, "Observaciones sobre la actio del lector. (De La Celestina a la sátira novohispana)», Escritos 26 (2002), 13-35.

Estudia, a partir del paratexto de la edición de la Comedia de Toledo, la actio, es decir, las instrucciones que se dan para leer la obra en voz alta. Se detiene, sobre todo, en la primera de estas recomendaciones: leer "entre dientes", procedimiento típicamente cómico con que se presentaban situaciones y personajes nada virtuosos.

2103. JARDIN, Jean-Pierre, «Amor dulce. Sensualité, érotisme et pornographie dans La Celestina», Les Langues Néo-Latines 347 (2008), 5-13.

Se examinan en este artículo los diferentes aspectos del amor (sensualidad, erotismo y pornografía) junto a las parafilias (zoofilia, fetichismo, voyeurismo y exhibicionismo) en $L C$, y se resalta la diferente visión de la pasión amorosa en los personajes masculinos y femeninos de la obra. 
2104. JARDIN, Jean-Pierre, "Célestine et les démons», en MARTIN, 81100.

El propósito del articulista es aclarar las creencias en la magia blanca y la magia negra en la época de la obra y propone la ambigüedad esencial que permite que los críticos modernos defiendan lo que resulta ser una doble lectura: o la eficacia de la magia en la trama de la obra o su no eficacia en ella, con razones sólidas. Toda interpretación de la magia no depende del autor, sino del lector. [JTS]

2105. KISH, Kathleen V., "Celestina as Chamaleon: The Early Translations", Celestinesca 33 (2009), 87-98.

Se analizan las primeras traducciones de $L C$, sobre todo, por el interés que esta suscitaba en la clase mercantil europea. Se destaca la importancia de dichos textos que nos permiten, a veces, solucionar pasajes oscuros y muestra cómo los traductores adaptaron la obra al nuevo contexto histórico-social en el que llevaron a cabo su tarea.

2106. LADERO QUESADA, Miguel Ángel, "Aristócratas y marginales: aspectos de la sociedad castellana en La Celestina», en su Países y hombres de la Edad Media (Granada: Universidad, 2007), 365-399.

Artículo publicado originalmente en Espacio, Tiempo y Forma [UNED] III/3 (1990), 95-120 y reseñado ya por JTS en Celestinesca 15.2 (1991), núm. 421.

2107. LARA ALBEROLA, Eva. «La hechicera en la literatura española del siglo XVI. Panorámica general». Lemir 14 (2010), 35-52. Web. (http:// parnaseo.uv.es/lemir.htm).

Análisis general de la figura de la hechicera en obras españolas del siglo XVI que tiene como objetivo principal el de reunir y analizar los diferentes textos que hacen referencia a dicho personaje y a la magia. Presenta una útil clasificación de los tipos de hechiceras hispánicas (celestinescas, clásicas y marginales) y trata, al final, también de la brujería.

2108. LÓPEZ IZQUIERDO, Marta, "Ruptura de la verosimilitud en la lengua de La Celestina: distribución de tres marcadores discursivos», Pandora 6 (2006), 59-77.

Se dedica especial atención al registro lingüístico informal empleado por todos los personajes de $L C$, caracterizado por un léxico y unas expresiones populares y coloquiales. Trata, en particular, de tres marcadores discursivos: alahé, por cierto, a osadas. 
2109. LÓPEZ-RÍOS, Santiago, "Ver la 'grandeza de Dios' en la Celestina: más allá del tópico de la hipérbole sagrada», en PAOLINI, 206-225.

Reconsidera la primera escena de LC y señala cómo, en realidad, no sólo se realiza una parodia del amor cortés, sino también de la hipérbole sagrada, lograda a través de una alusión sutil y blasfema a la divinidad. También llama la atención en los pasajes de la obra en que se mezcla lo espiritual con lo obsceno (las oraciones más bien pragmáticas y "carnales», el cordón en mano de Calisto, etc.).

2110. LUCÍA MEGÍAS, José Manuel, «Reflexiones en torno a las plataformas de edición digital: el ejemplo de La Celestina», en PAOLINI, 226-251.

Algunas consideraciones sobre el medio digital como difusión del saber y análisis de algunos portales de la Red que ofrecen el texto de $L C$ tanto en edición facsímil como en edición crítica. Por último, se presentan propuestas para mejorar lo que se ha hecho hasta el momento (importancia de la interactividad, la Web 2.0, las plataformas de edición digital, etc.).

2111. LUESAKUL, Pasuree, "Lilit Pralor y La Celestina: un estudio comparado de la literatura amorosa entre Tailandia y España», Celestinesca 33 (2009), 101-113.

La obra maestra tailandesa Lilit Pralor presenta muchos rasgos en común con LC: una trama que rueda alrededor del amor loco-ilícito, la presencia de la magia y un final trágico, entre otros aspectos. Las dos fueron compuestas casi en los mismos años y en un momento en que los dos respectivos países no tenían ningún contacto entre ellos, una demostración de la universalidad de ciertos temas y de cómo estos se desarrollaron originalmente en diferentes contextos culturales y literarios.

2112. MARTIN, Georges, "Púsete con señor que no le merescías descalçar': Celestina y la Inquisición», en MARTIN, 31-60.

Una interesante búsqueda con ojos atentos a los variables matices semánticos de los secretos sobre el origen de varios personajes, matices que hay que descubrir por debajo de las palabras, en una época de transición desde una cierta cohesión social a una sociedad monoteísta bajo la Inquisición, que hace que los secretos y los orígenes se guarden o se disfracen. Tiene mérito el uso generoso del texto celestinesco en el estudio y en las notas. [JTS] 
2113. MARTIN, Georges, ed., Fernando de Rojas, La Celestina. Comedia o tragicomedia de Calisto y Melibea. Paris: Ellipses, 2008.

Una colección de diez estudios, cada uno reseñado en este suplemento bajo MARTIN y páginas.

2114. MENCÉ-CASTER, Corinne, "Présence et modulations du sujet dans le discourse. Entre vouloir et devoir: Pármeno face à Célestine (acte I)», en MARTIN, 119-137.

Este detallado análisis del largo diálogo entre Pármeno y Celestina demuestra cómo este arte requiere ser considerado como un elemento esencial de la constitución de su enunciación y no como sólo un marco externo. Hay en este diálogo frases de la ética y de la ontología que son vitales para la comprensión de la obra en general. [JTS]

2115. MIAJA, María Teresa, "La Celestina», en Temas de literatura medieval española, eds. A. González y M. T. Miaja (Manuales de Medievalia 4, México D.F.: UNAM, 2006), 75-84.

Ensayo general acerca de $L C$ que trata de su estructura, autoría, argumento, género, estilo, espacio y tiempo, personajes e interpretaciones.

2116. MIAJA, María Teresa, "Entablando diálogos en La Celestina», en Actas del XV Congreso de la Asociación Internacional de Hispanistas "Las dos orillas", Monterrey, México. Del 19 al 24 de julio de 2004, eds. B. Mariscal y A. González (México, D. F.: Fondo de Cultura Económica, Asociación Internacional de Hispanistas, Tecnológico de Monterrey, El Colegio de México, 2007), t. 1, 421-431.

Análisis del diálogo y de la función que desempeña en la obra.

2117. MIAJA, María Teresa, "El sentido del diálogo en La Celestina», en Temas, motivos y contextos medievales, eds. A. González, C. Company, L. von der Walde Moheno (Publicaciones de Medievalia 33, México, El Colegio de México, UNAM, UAM, 2008), 173-183.

De los diferentes tipos de diálogo que se dan en $L C$, se ocupa, en particular, del de réplicas breves y rápido. Se analiza su función (representación de situaciones de especial tensión dramática y sugerencia de tratos de complicidad) y su importancia a lo largo de la obra.

2118. MIAJA, María Teresa, "Elementos petrarquistas en La Celestina», en Petrarca y el petrarquismo en Europa y América, ed. Mariapía Lamberti (México, Comitato Nazionale per le Celebrazioni del VII centenario della nascita di Francesco Petrarca, Facultad de Filosofía y Letras, UNAM, 2006), 315-320. 
La autora analiza de nuevo los préstamos de Petrarca que se encuentran a lo largo de $L C$ y, en particular, los que vienen del De remediis utriusque fortunae. Confirma lo destacado por Deyermond (amor, amistad y adversidad como temas principales de la presencia de Petrarca en la obra) y considera también importantes otros argumentos como el buen nacimiento, la buena crianza, la honra, el honor y, sobre todo, la juventud versus la vejez.

2119. MIGUEL MARTÍNEZ, Emilio de, "La Celestina, madre rehusada del teatro español», en De "La Celestina" a "La vida es sueño»: Cinco lecciones sobre obras universales del teatro clásico español, ed. Germán Vega (Valladolid-Olmeno: Universidad, Ayuntamiento, 2009), 13-44. Ilustrada.

Es una firme defensa de la teatralidad de LC. El autor leyó buen teatro (Terencio) y no sorprende que lo haya podido crear. Como obra sin descendencia en el teatro del Siglo de Oro, Miguel Martínez la considera una "madre rehusada». Sabe argumentar en contra de los que critican aspectos de la obra considerados no-teatrales y defiende muy bien todas las marcas teatrales que ostenta, lo que lo lleva a postular que la verdad teatral no es lo mismo que la verdad objetiva. [JTS]

2120. MONTOYA RAMÍREZ, Ma Isabel, «La influencia clásica en La Celestina. El mito de Dido y Eneas», en Homenaje a la profesora $M^{a}$ Dolores Tortosa Linde, ed. Remedios Morales Raya (Granada: Universidad, 2003), 345-353.

Analiza el episodio de Dido y Eneas en la Eneida y las Heroidas en relación con $L C$, señalando los puntos en común que estas obras comparten (los paralelismos entre los personajes: Venus / Celestina, Eneas / Calisto, y Dido / Melibea; el modus operandi parecido de los dos intermediarios para llevar a cabo el engaño; el miedo de las amadas a que las abandonen después de entregarse; y el suicidio final de las dos jóvenes).

2121. MORROS, Bienvenido, "Melancolía y amor hereos en La Celestina», Revista de poética medieval 22 (2009), 133-183.

El amor como enfermedad fue asociado por la medicina bizantina y medieval con la melancolía, dado que presentaba con esta muchos síntomas en común. Sin embargo, algunos médicos prescribían como cura para las dos enfermedades la relación sexual, acto muy poco idóneo para quien, por definición, tenía temperamento frío y seco y, consiguientemente, falta tanto de materia espermática como de deseo. Arnaldo de Vilanova y otros médicos intentaron resolver estas contradicciones diferenciando al amor hereos de la melancolía, y concluyeron que en realidad los que padecían este malestar tenían un tempera- 
mento sanguíneo o colérico. Seguramente los autores de $L C$ estaban al tanto de estas teorías y las siguieron al caracterizar a algunos de los personajes de la obra (la pareja de jóvenes enamorados, Pármeno y Areúsa) como enfermos de amor.

2122. MORROS, Bienvenido, "Los prólogos en prosa de La Celestina», Celestinesca 33 (2009), 115-125.

Rojas compuso dos prólogos, uno por cada versión de su obra maestra, siguiendo como modelo la carta introductoria de Enea Silvio Piccolomini a su Historia de duobus amantibus. En el primero, el autor de $L C$ dedica la obra a un amigo suyo agradeciéndole los favores recibidos. En el segundo, explica que ha decidido ampliar los encuentros de los dos enamorados para cumplir con la petición de sus jóvenes lectores. El final trágico tanto de la obra del humanista italiano como de la del escritor castellano se debió a la voluntad de disuadir a seguir el amor carnal.

2123. NAVARRO DURÁN, Rosa, «La complicidad con otros textos: las lecturas que asoman en las obras literarias", Castilla. Estudios de Literatura 0 (2009), 204-229. Web. (http://www5.uva.es/castilla/index.html)

Además de indicar algunas posibles fuentes del Lazarillo, del Quijote y de la Segunda parte del Lazarillo, en el segundo apartado se atiende a $L C$ y se recuerdan primero los pasajes en que Rojas demuestra haber leído a Jorge Manrique y se señala luego un poema de éste que habría podido dar al autor la idea de la desastrosa y por nada noble muerte de Calisto.

2124. PAOLINI, Devid, coord., "De ninguna cosa es alegre posesión sin compañia». Estudios celestinescos y medievales en honor del profesor Joseph Thomas Snow. New York: Hispanic Seminary of Medieval Studies, 2010, 2 tomos.

El primer tomo recoge 17 artículos sobre $L C$ dedicados al homenajeado y todos reseñados aquí bajo PAOLINI y páginas.

2125. PAOLINI, Devid. «Una curiosa coincidencia: Semplonio y Calisto personajes de una antigua farsa florentina", en AOLINI, 252-271.

Se da a conocer y se transcribe el texto de una antigua farsa florentina de finales del siglo XV o principios del XVI cuyos personajes principales son el viejo Semplonio y el joven Calisto. Este último quiere casarse y pide consejo a su amigo que le nombra, una tras otra, todas las desventajas del matrimonio. 
2126. PAOLINI, Devid, "El gesto obsceno 'dar las higas' en Celestina», Celestinesca 33 (2009), 127-141.

En dos pasajes de la obra aparece esta señal obscena que presenta un solo antecedente literario castellano. Más numerosos, y reunidos en un apéndice al final, son los textos y documentos de la península italiana donde se registra dicho gesto.

2127. PARDO, Madeleine, y Hélène THIEULIN-PARDO, "Sous le manteau de Célestine», en MARTIN, 101-118.

Este artículo presenta una rica lectura de la escena del auto vi cuando Calisto expresa el deseo de haber estado debajo del manto de Celestina en casa de Melibea (auto IV). El parodiado amante, Calisto, se pone en ridículo, pero la alcahueta piensa aprovecharse de los agujeros del manto, y de este breve diálogo se abren puertas a meditaciones sobre dicha prenda de la vieja que afectan al resto del texto. [JTS]

2128. PARELLO, Vincent, "Aquel mudar de trajes, aquel derribar y renovar edificios': la modernité historique-sociale de La Celestina», en MARTIN, 7-20.

Demostrando una lectura pormenorizada del texto, el autor analiza la evolución de una mentalidad suntuaria en la sociedad pre-capitalista que rezuma casi cada página de LC. Es un materialismo no sólo histórico, sino también espiritual. [JTS]

2129. PARRILLA, Carmen, "Para la historia de la recepción de Celestina: ecos y menciones en textos poéticos del siglo XVI», en PAOLINI, 272290.

Da a conocer unos cuantos textos poéticos del siglo XVI donde se hace referencia a la alcahueta Celestina, ampliando, así, nuestros conocimientos acerca de la recepción de la obra.

2130. PASCUAL BUXÓ, José Pascual, "Las vueltas de Sor Juana», Nuevo Texto Crítico 4.7 (enero-junio 1991), 197-204.

El autor repasa aquí las serias dudas que quedan en torno a la supuesta colaboración o coautoría (con Salazar y Torres) de El encanto de la hermosura y la Segunda Celestina. Frente a Octavio Paz, a Pascual Buxó los argumentos avanzados hasta la fecha no le han convencido. [JTS]

2131. PÉREZ, Joseph, "La Célestine, livre converso ou livre de converso», en MARTIN, 21-29.

El historiador contribuye en este artículo a una revisión del subtexto religioso de $L C$ y demuestra que no sólo hay críticas al catolicismo 
sino también al nuevo judaísmo materialista de finales del siglo Xv. Termina exponiendo su opinión de que la obra está inmersa en un nuevo laicismo secular. [JTS]

2132. PORRAS, Georges Yuri, "La Celestina (1499): Amor hereos y su terapia-causa musical en Calixto y Melibea", en El cuerpo enfermo. Representaciones e imágenes de la enfermedad, eds. R. de la Fuente Ballesteros y J. Pérez Magallón (Valladolid: Universitas Castellae, 2006), 199-209.

Estudia el amor hereos de Calisto y Melibea (y su criada Lucrecia) en asociación con la música, y muestra cómo esta es, al mismo tiempo, alivio para ellos e intensificadora de su pasión extrema, lo que lleva a un círculo vicioso.

2133. PORRAS, George Yuri, «La música como terapia y como hechizo en La Celestina (1499) de Fernando de Rojas y en La segunda Celestina (1534) de Feliciano de Silva», Crítica Hispánica XXIX.1-2 (2007), 271-292.

Analiza la relación entre la música y el mal de amores tanto en $L C$ como en La Segunda Celestina (1534), y se ocupa también de la música como causa y cura del amor hereos (Calisto y Melibea / Felides y Polandria) y nimis amor (Lucrecia / Pandulfo).

2134. PUERTO MORO, Laura, Obra conocida de Rodrigo de Reinosa. Serie Mayor, n. 7, San Millán de la Cogolla: Instituto Biblioteca Hispánica del CiLengua, 2010.

En el segundo capítulo de la primera parte (Poesía bufonesca), se dedican unas cuantas páginas a las Rufianas y rameras (51-65), a las Comadres (65-76) y, por último, a las "Comadres» $y$ "Celestina» (77-94).

2135. RASCÓN PEÑAS, $M^{a}$ Francisca, «La moda masculina en el siglo XV a través del léxico de una obra literaria", en Moda y sociedad. La indumentaria: estética y poder, ed. M ${ }^{a}$ I. Montoya Ramírez (Granada: Universidad, 2002), 415-421.

Se ocupa de los trajes de los personajes masculinos en $L C$ para evidenciar cómo, aun compartiendo los mismos vestidos señor y criados, estos se diferenciaban por el color, la calidad del material con el que estaban hechos y también por su estado de conservación.

2136. RICO, Francisco, "Crítica textual y transmisión impresa (Para la edición de La Celestina)", en Imprenta y crítica textual en el Siglo de Oro, dir. F. Rico, eds. P. Andrés y S. Garza, (Valladolid: Universidad de Valladolid, Centro para la Edición de los Clásicos Españoles, 2000), 223-241. 
Rico comenta pasajes que combinan lecturas de la CCM y la TCM, y analiza cómo la actuación de los que trabajaban en la imprenta (correctores, cajistas, etc.) podía afectar al manuscrito que imprimían. [JTS]

2137. RODRÍGUEZ PUÉRTOLAS, Julio, «La Celestina o la negación de la negación", Verba hispanica XV/a (2007), 17-34.

En su análisis de los personajes celestinescos, el autor muestra cómo la aparición de una nueva clase social (la burguesía) llevó al fetichismo del dinero y a la cosificación, lo que provocó una crisis del sistema tradicional de valores, como la amistad, la solidaridad y la comunicación humana. Presenta también, al final, una nueva interpretación, más materialista, de la figura de Pleberio y de su lamento después del suicidio de su hija Melibea, tras lo que concluye que en $L C$ se presenta una crítica demoledora de la sociedad de la época sin posibilidad de salida (un artículo con el mismo título y por el mismo autor apareció en Literatura, historia, alienación. Barcelona: Planeta, 1976, 147-171. Se reseñó en el suplemento bibliográfico de Celestinesca 1.1 [1977], pág. 31, S16).

2138. ROHLAND DE LANGBEHN, Regula, «Viejas y jóvenes: la convivencia entre mujeres del ambiente prostibular en textos literarios del período moderno temprano", en PAOLINI, 291-311.

Estudio comparativo del personaje de la prostituta en $L C$, la celestinesca y la picaresca femenina, con particular referencia a la sífilis

2139. ROIG MIRANDA, Marie, "Le comique dans La Celestina», Les Langues Néo-Latines 347 (2008), 15-31.

Se consideran los diferentes tipos de comicidad (de personajes, situación, gestos y palabras) presentes en $L C$, con el objetivo de avanzar algunas hipótesis sobre la posible función de lo cómico en la obra.

2140. ROJAS, Fernando de, La Celestina, ed. E. Borrego. Madrid: Cooperación Ed., 2009. Rústica, 233 pp.

Es la tercera reimpresión de esta edición, basada en la de Zaragoza 1507 y con los argumentos de la de Valencia de 1514. Con notas y sin ilustraciones. [JTS]

2141. ROJAS, Fernando de, Tragicomedia de Calisto y Melibea. Ed. facsímil de la edición de Alcalá de Henares: Juan de Lequerica, 1575. Barcelona: Universidad, 2009. 458 pp.

Edición en $12^{\circ}$, hermosamente reproducida, y presentada por Rafael M. Mérida Jiménez, con bibliografía. Se distingue por sus 8 pasajes tachados, aclarados en las páginas de presentación. [JTS] 
2142. ROJAS, Fernando de, Celestina, trad. al inglés por Peter Bush, introd. de Juan Goytisolo. Cambridge, UK: Dedalus, 2009. Rústica, 219 pp.

$L C$ se ha novelizado en esta versión y los actos se han sustituido por capítulos. La presencia dentro de la ficción de un narrador cambia la recepción. Los preliminares y posliminares aparecen todos al final de los 21 capítulos. No hay notas para explicar los nombres mitológicos u otras cosas de la España del siglo XVI. La esencia del original se capta en un inglés puesto al día. [JTS]

2143. ROUBAUD, Sylvia, "Les derniers mots de Melibea», en MARTIN, 177-186.

El artículo nos ofrece un pormenorizado retrato psicológico de una Melibea en sus momentos finales, cruel pero consecuente con sus apariciones en los actos anteriores. Reconoce la autora que lo que ella hace es una vuelta a otro modelo de análisis literario, pero los resultados son una aportación al estudio de la caracterización de la heroína de la obra. [JTS]

2144. SALES DASÍ, Emilio J., "Ecos celestinescos en el Lisuarte de Grecia de Feliciano de Silva», Tirant. Butlletí Informatiu i Bibliogràfic de Literatura de Cavalleries 3 (2000), sin paginación. Web. (http://parnaseo.uv.es/ tirant.htm)

Señala posibles aspectos de $L C$ que pudieron influir en la composición del Lisuarte de Grecia, obra que Feliciano de Silva escribió en sus años juveniles.

2145. SÁNCHEZ, Antonio y Remedios PRIETO, "Sobre la 'composición' de La Celestina y su anónimo 'auctor'», Celestinesca 33 (2009), 143-171.

Un detenido estudio de la obra que se divide en dos partes: en la primera se analizan algunos diálogos que no encajan con el sentido general de $L C$ y que parecen formar parte de un texto anterior (una comedia humanística en vernáculo); en la segunda se intenta demostrar cómo en realidad Rojas fue el amigo/destinatario que recibió un texto ya completo que luego amplió y cambió dándole un final trágico.

2146. SCHMIDHUBER DE LA MORA, Guillermo, Sor Juana Inés de la Cruz y "La Gran Comedia de la Segunda Celestina», ed. de la comedia al cuidado de Olga Martha PEÑA DORIA. Col. Visiones y Tentaciones II, México, D.F.: Instituto Mexiquense de Cultura, 2005. Rústica, 431 pp.

Estudio y edición de La Gran Comedia de la Segunda Celestina de Agustín de Salazar y Torres que se publicó incompleta en 1676, un año después de la muerte de su autor. El segundo capítulo se dedica al 
análisis de la celestinesca y los demás al texto en cuestión. Se propone la coautoría de Sor Juana Inés de la Cruz.

2147. SEGURA, Cristina, "Mujeres en el mundo urbano. Sociedad, instituciones y trabajo", en Historia de las mujeres en España y América Latina. I. De la Prehistoria a la Edad Media, dir. I. Morant, coords. Má. Querol, C. Martínez, D. Mirón, R. Pastor y A. Lavrin (Col. Historia. Serie Menor. Madrid: Cátedra, 2005), 517-545.

Análisis del trabajo remunerado de las mujeres en las ciudades medievales y de los lugares en que ejercían sus oficios y pasaban su tiempo ellas solas (la fuente, el horno, el lavadero) o en común con los hombres (el mercado, los templos y las celebraciones religiosas). Trata, también, de la sociedad de la época y hace, al final, dos breves referencias a $L C$.

2148. SEVERIN, Dorothy S., "The Lives and Times of Celestina's Followers», en PAOLINI, 312-316.

Una mirada al pasado de algunos de los personajes celestinescos (Pármeno, Sempronio, Areúsa, Elicia, Lucrecia, Pleberio, Alisa y Calisto).

2149. SEVILLA ARROYO, Florencio, "Amor, magia y tiempo en La Celestina», Celestinesca 33 (2009), 173-214.

Se centra en el análisis del «amor», la "magia» y el «tiempo» en $L C$, considerada como reprobatio amoris. En particular, subraya como la maestría en el uso de los dos últimos elementos tiene como efecto principal el de transformar en una obra maestra una comedia de otro modo insignificante.

2150. SOLANA SEGURA, Carmen, "La Tragicomedia de Polidoro y Casandrina como distorsión del paradigma celestinesco", en Actas del I Congreso Internacional de filología hispánica: jóvenes investigadores, ed. J. A. Calzón García et al. (Oviedo: Universidad, 2008), 729-735.

Esta obra descubierta por Stefano Arata fue fijada por él como la "quinta Celestina», pero aquí la autora analiza con lupa las radicales diferencias entre Polidoro y la celestinesca derivada de la de Calisto y Melibea hasta poder llamar a esta obra una "distorsión» de sus planteamientos. Más tiene que ver con la picaresca femenina. [JTS]

2151. SOLANA SEGURA, Carmen, "Hacia una datación de la Tragicomedia de Polidoro y Casandrina: datos históricos e influencias literarias", Celestinesca 33 (2009), 217-231.

Basándose en datos históricos y literarios, propone como probable fecha de composición de la obra la última década del siglo XVI o la pri- 
mera del XVII, con lo que pospone así la datación más temprana (1564) que había indicado Stefano Arata.

2152. SNOW, Joseph T., "Celestina en la corte de los Reyes Católicos», en La literatura en la época de los Reyes Católicos, eds. N. Salvador Miguel y C. Moya García (Col. Biblioteca Áurea Hispánica 52. Madrid-Frankfurt: Iberoamericana, Vervuert, Universidad de Navarra, 2008), 293-303.

No obstante el éxito de que gozó LC desde su primera aparición no se ha podido encontrar ninguna documentación acerca de su recepción en la corte de los Reyes Católicos. Sí hay información acerca de su fortuna durante la época de Fernando e Isabel, pero nada que pueda relacionarse con los monarcas o su entorno. Probablemente la obra se conoció, aunque su anticlericalismo, su atención a personajes bajos y marginados, su amoralidad, suscitaron reacciones diferentes entre sus posibles lectores cortesanos.

2153. SNOW, Joseph T., "Celestinesca y Alan Deyermond», Celestinesca 33 (2009), 13-15.

Se recuerdan el aporte y apoyo fundamentales del profesor Alan Deyermond a la revista Celestinesca.

2154. SNOW, Joseph T., "Celestina: documento bibliográfico (suplemento número 31)», Celestinesca 33 (2009), 275-320.

Snow agrega 200 nuevas entradas al suplemento bibliográfico que desde 1985 suman ya 2.059 .

2155. SNOW, Joseph T., "Talking the Talk': Ventriloquism in Celestina», en 'Recuerde el alma dormida'. Medieval and Early Modern Spanish Essays in Honor of Frank A. Dominguez, eds. J. K. Moore, Jr. y A. Duque (Homenajes 35. Newark, DE: Juan de la Cuesta, 2009), 283-304.

Se ocupa de la importancia de la "voz»y de las "voces» en la obra, y de los personajes ventrílocuos, esto es, de aquellos que hablando imitan la voz de otros.

2156. SNOW, Joseph T., "Celestina y el concepto de tiempo dramático», en Expresiones de la cultura y el pensamiento medievales, eds. L. von der Walde Moheno, C. Company y A. González (Publicaciones de Medievalia 37. México D.F.: El Colegio de México, UNAM, UAM, 2010), 19-39.

En su análisis del tiempo dramático en $L C$, con particular atención al tiempo inferido, el estudioso defiende y amplía, aportando nuevos datos, la posición de Asensio que señalaba la necesidad de que transcurrieran unos días entre el primer encuentro de los dos jóvenes enamorados y la confesión de Calisto a Sempronio. Y esto con el fin 
de que pudiera apreciarse de forma mejor la profundidad de la obra. Al mismo tiempo presenta su propuesta de división de las secuencias temporales de la obra en cinco apartados delimitados, cada uno de ellos, por una secuencia no representada.

2157. SNOW, Joseph T., «Los trayectos urbanos del mundo celestinesco", en Actas del IX Congreso Internacional de Caminería Hispánica (Cádiz 2008), ed. M. Criado de Val (Guadalajara: AACHE Ediciones, 2010), en CDRom [sin paginación, en la Sección 'Caminería literaria', 9 páginas].

Reconstruye, a través de los diálogos y monólogos de los personajes (y sus referencias a calles, casas, iglesias, plazas, etc.), los diferentes trayectos urbanos (explícitos e implícitos) de $L C$.

2158. TAYLOR, Barry, "Reading Celestina in the Sixteenth and Seventeenth Centuries», en PAOLINI, 317-324.

Juan de Valdés, en su Diálogo de la lengua, reprochaba a $L C$ su propensión a la repetición, a los sinónimos, a las similitudes, etc. Sin embargo, Miguel de Salinas, en su Rhetórica en lengua castellana (1541), alababa dicho estilo y recomendaba su lectura a todos los que quisieran mejorar su escritura y su lenguaje. Además, las ediciones bilingües (en francés y español) de la obra maestra impresas en el siglo xvil, dejan patente su función pedagógica y muestran cómo se la consideraba un ejemplo del estilo copioso.

2159. TOZER, Amanda J. A., "Tristán, Sosia and Centurio as Burlesque Figures», La corónica 32.2 (2004), 151-170.

Intenta rescatar la importancia de los tres personajes citados en el título, señalando la posibilidad de que Rojas intentase, a través de ellos, nuevos caminos literarios y dramáticos. Quiso, además, satisfacer los deseos de su público lector/oidor y llenar un vacío dialógico creado por la muerte literaria de la vieja alcahueta y los dos sirvientes, que tanto papel habían tenido en la primera parte de la obra.

2160. VALLE DE RICOTE, Gofredo (seudónimo de Govert Westerveld), El libro perdido de Lucena: 'Tractado sobre la muerte de Don Diego de Azevedo', tomo 2 de Los tres autores de la "Celestina". Murcia: Autor, 2008. $\mathrm{ix}+139 \mathrm{pp}$.

Conjetura que Fernando de Rojas usó el seudónimo de Luis de Lucena. Trata de la posible amistad entre Rojas/Lucena y Alonso III de Fonseca y Ulloa, y la del padre del primero, el protonotario Juan Ramírez de Lucena, con el progenitor del segundo, Alonso de Fonseca y Acevedo, Arzobispo de Santiago, Patriarca de Alejandría y miembro del Consejo Real. 
2161. VALLE DE RICOTE, Gofredo (seudónimo de Govert Westerveld), El misterioso autor Juan del Encina, tomo 3 de Los tres autores de la "Celestina». Murcia: Autor, 2009. viii + pp. 1-358.

Contiene los diez primeros capítulos de un estudio en dos tomos (ver la entrada siguiente). Presenta a Juan Ramírez de Lucena como el primer autor de $L C$, y a Juan del Encina como uno de los posibles continuadores de la obra maestra española. De este último afirma que usó luego el seudónimo de Bartolomé de Torres Naharro y Francisco Delicado, y trata de su posible papel de impresor.

2162. VALLE DE RICOTE, Gofredo (seudónimo de Govert Westerveld), La Celestina: un señuelo, Fernando de Rojas, y un autor velado, Juan del Encina, tomo 4 de Los tres autores de la "Celestina". Murcia: Autor, 2009. viii + pp. 359-623.

Los capítulos 11-23 se dedican a diferentes asuntos: la biografía de Rojas y Encina, la biblioteca del primero, Alonso de Proaza, el traductor de LC al italiano, Pedro Manuel Ximénez de Urrea, la Comedia Thebayda, Hernando del Castillo, la Carajicomedia, el Cancionero LB1 (editor de estos dos últimos fue Encina) y el auto de Traso.

2163. VASVÁRI, Louise O., "Further Glosses on the Vocabu(r)lario of the Celestina: III, the 'Fowl' Humour of desplumar», en PAOLINI, 325-345.

Tercera aportación al vocaburlario de $L C$. Después de analizar los términos «landrecillo» y "cola de alacrán» en el famoso diálogo entre Pármeno y la alcahueta en el acto I (artículo ya reseñado por Snow en Celestinesca 33 [2009], núm. 2053), y ocuparse del 'dolor de muelas' de Calisto (ibid., núm. 2054), trata aquí de la acepción de 'desplumar' (y de su fuerte connotación erótica) en el último encuentro íntimo entre los dos enamorados (acto XIX) antes de la tragedia final.

2164. VICENTE HERNANDO, César de, «Una lectura política de las coplas de Hernando de Vera», Verba hispanica XV/a (2007), 45-58.

En este análisis de las coplas de Hernando de Vera hay dos breves alusiones a $L C$ con el propósito de mostrar la diferencia entre la ideología materialista presente en aquellas (crítica a los monarcas por la mala administración del reino) y la visión «espiritual» de esta y otras composiciones contemporáneas (llamada en causa de Dios e/o impotencia frente a un mundo hostil, ciego y sordo).

2165. VIDAL DOVAL, Rosa, «Erotismo, amor y violencia en Celestina: consideraciones a la luz de La llama doble», Celestinesca 33 (2009), 233-245. 
En su ensayo La llama doble, Octavio Paz diferencia el amor del erotismo y habla del deseo como de algo oscuro y destructor. Se aplica esta lectura a $L C$, considerándose el amor en relación a la violencia. La conclusión es que todo lo mueve el deseo y su vertiente destructora se desprende de la violencia en la relación entre los dos jóvenes enamorados.

2166. WHINNOM, Keith, The textual history and authorship of "Celestina", ed. Jeremy Lawrance. Papers of the Medieval Hispanic Research Seminar 52. London: Queen Mary-University of London, 2007. Rústica, $104 \mathrm{pp}$.

Entrada de la que ya se ha tratado en el último suplemento bibliográfico (Celestinesca 33 (2009), núm. 2059), y de la que se señalan las dos siguientes reseñas:

Medium Aevum LxxviII (2009), 154-155, Juan-Carlos Conde. Bulletin of Spanish Studies 87.5 (July 2010), 664-666, Nancy F. Marino.

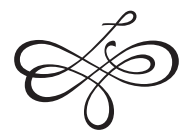


